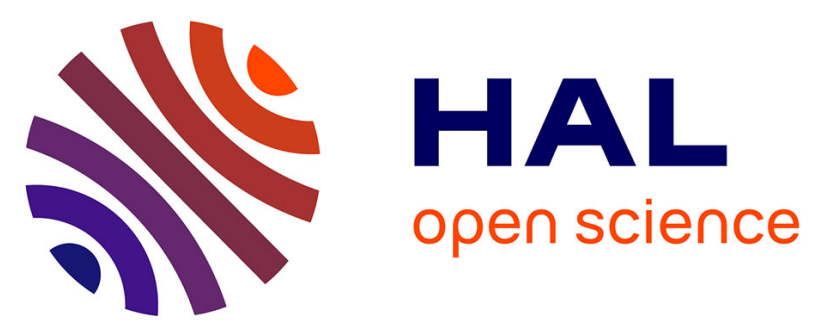

\title{
The transmembrane domain of the SNARE protein VAMP2 is highly sensitive to its lipid environment
}

Zahia Fezoua-Boubegtiten, Benoit Hastoy, Pier Scotti, Alexandra Milochau, Katell Bathany, Bernard Desbat, Sabine Castano, Reiko Oda, Jochen Lang

\section{- To cite this version:}

Zahia Fezoua-Boubegtiten, Benoit Hastoy, Pier Scotti, Alexandra Milochau, Katell Bathany, et al.. The transmembrane domain of the SNARE protein VAMP2 is highly sensitive to its lipid environment. Biochimica et Biophysica Acta:Biomembranes, 2019, 1861 (3), pp.670-676. 10.1016/j.bbamem.2018.12.011 . hal-02348321

\section{HAL Id: hal-02348321 \\ https://hal.science/hal-02348321}

Submitted on 21 Oct 2021

HAL is a multi-disciplinary open access archive for the deposit and dissemination of scientific research documents, whether they are published or not. The documents may come from teaching and research institutions in France or abroad, or from public or private research centers.
L'archive ouverte pluridisciplinaire HAL, est destinée au dépôt et à la diffusion de documents scientifiques de niveau recherche, publiés ou non, émanant des établissements d'enseignement et de recherche français ou étrangers, des laboratoires publics ou privés.

\section{(ㅇ)(1) $\$$}

Distributed under a Creative Commons Attribution - NonCommerciall 4.0 International 


\section{The Transmembrane Domain of the SNARE Protein VAMP2 is Highly Sensitive to its Lipid Environment}

Zahia Fezoua-Boubegtiten ${ }^{\mathrm{a}}$, Benoit Hastoy ${ }^{\mathrm{b}}$, Pier Scotti, Alexandra Milochau, Katell

Bathany, Bernard Desbat, Sabine Castano, Jochen Lang*, Reiko Oda*.

Laboratoire de Chimie et Biologie des Membranes et Nano-objets, CNRS UMR 5248, Université de Bordeaux, Allée Geoffroy St Hilaire, F-33600 Pessac, France.

Corresponding authors :

Reiko ODA, Laboratoire de Chimie et Biologie des Membranes et Nano-objets, CNRS UMR 5248, Université de Bordeaux, Allée de St Hilaire, F-33600 Pessac.

e-mail r.oda@cbmn.u-bordeaux.fr, phone +33 540002229

Jochen LANG, Laboratoire de Chimie et Biologie des Membranes et Nano-objets, CNRS UMR 5248, Université de Bordeaux, Allée de St Hilaire, F-33600 Pessac.

e-mail j.lang@ cbmn.u-bordeaux.fr, phone +33 540006871

present address :

${ }^{\text {a }}$ Laboratoire de Bioélectrochimie et Spectroscopie, UMR 7140. Université de Strasbourg.

4 rue Blaise Pascal, F-67000 Strasbourg, France.

${ }^{\mathrm{b}}$ Oxford Centre for Diabetes, Endocrinology and Metabolism, Radcliffe Department of Medicine, University of Oxford, Oxford OX3 7LE, UK. 


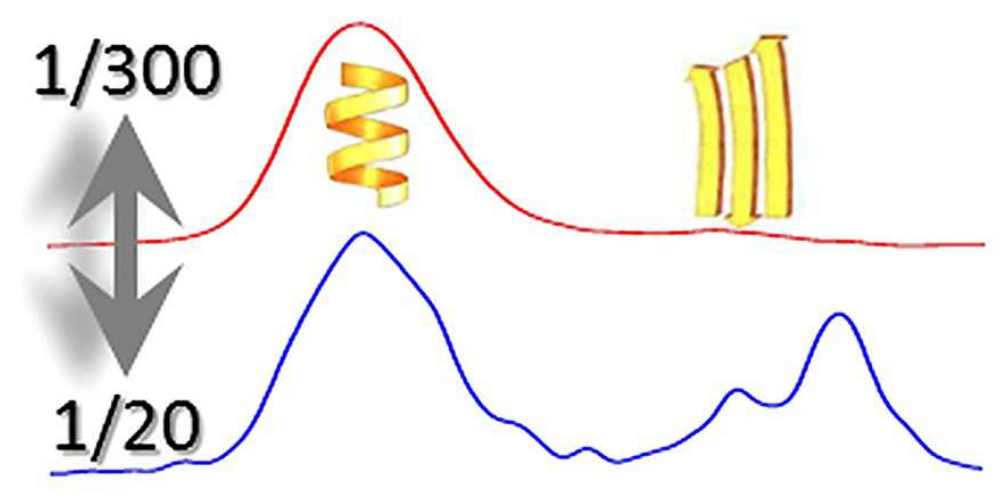

\section{HIGHLIGHTS}

- The transmembrane domain (TMD) of VAMP2 and lipids influence membrane fusion

- VAMP2-TMD undergoes concentration dependent reversible structural changes in bilayers

- VAMP2 TMD structures are highly sensitive to the composition of the lipid environment

- Mutating 2 central residues, crucial for exocytosis, increases $\beta$-sheet content

- The same mutation increases acyl chain perturbation 


\section{ABBREVIATIONS}

ATR, attenuated total reflection ;DMPC, 1,2-dimyristoyl-sn-glycero-3phophatidylcholine;DOPC, 1,2-dioleoyl-sn-Glycero-3-Phosphocholine;DOPS, 1,2-dioleoylsn-glycero-3-phosphoserine; FTIR, Fourier transform infrared ; $\mathrm{R}_{\mathrm{i}}$, peptide to lipid ratios; SNARE, soluble NSF attachment receptor; TMD, transmembrane domain; VAMP, vesicle associated membrane protein or synaptobrevin; VAMP2 ${ }_{\mathrm{TM} 22}$, VAMP2 transmembrane domain; 


\begin{abstract}
Neurotransmitter and hormone exocytosis depends on SNARE protein transmembrane domains and membrane lipids but their interplay is poorly understood. We investigated the interaction of the structure of VAMP2, a vesicular transmembrane SNARE protein, and membrane lipid composition by infrared spectroscopy using either the wild-type transmembrane domain (TMD), VAMP $2_{\mathrm{TM} 22}$, or a peptide mutated at the central residues $\mathrm{G}_{100} / \mathrm{C}_{103}$ (VAMP2 ${ }_{\mathrm{TM} 22} \mathrm{VV}$ ) previously identified by us as being critical for exocytosis. Our data show that the structure of VAMP2 $2_{\mathrm{TM} 22}$, in terms of $\alpha$-helices and $\beta$-sheets is strongly influenced by peptide/lipid ratios, by lipid species including cholesterol and by membrane surface charges. Differences observed in acyl chain alignments further underscore the role of the two central small amino acid residues $\mathrm{G}_{100} / \mathrm{C}_{103}$ within the transmembrane domain during lipid rearrangements in membrane fusion.
\end{abstract}

\title{
Keywords
}

ATR-infrared spectroscopy, Synaptobrevin, Exocytosis, SNARE proteins, cholesterol, phospholipids. 


\section{Introduction}

Fusion of proteolipid membranes forms the base of events such as intracellular vesicular transport as well as exocytosis in neurotransmission or hormone secretion [1]. A set of evolutionary highly conserved membrane proteins, the SNARE proteins, plays a major role within this process. These proteins are characterized by a cytosolic SNARE motif able to form a coiled coil consisting of four parallel helices termed the core complex [2, 3]. During exocytosis, the single-span integral membrane proteins VAMP/synaptobrevin, (localized at vesicle membranes), and syntaxin 1 in the plasma membrane, interact through their cytosolic SNARE domains to form the SNARE core complex $[2,3]$. The $\mathrm{N}$ - to C-terminal zippering of this coiled-coil locally approaches the two adjacent membranes, thus bridging the two compartments [4]. Exocytosis subsequently proceeds through fusion of the adjacent membrane leaflets and formation of a stalk $[5,6]$. Finally full fusion and release of soluble cargo occurs via the creation of a fusion pore which may further extend and lead to the diffusion of vesicular membrane components into the plasma membrane [7]. A number of isoforms have been identified for VAMP/synaptobrevin, the isoform VAMP2 is required for neuroexocytosis at the synapse [8] and for the fusion of peptide-hormone containing large dense core vesicles in endocrine cells [9].

The role and structure of the soluble SNARE domains and the juxtamembrane domains of the SNARE protein VAMP2 in membrane fusion are reasonable well understood $[1,10]$ whereas the structure and potential role of the transmembrane domain remained controversial [11-15, 16 ]. Membrane fusion proceeds through distinct stages in reconstituted systems and in live cells: hemifusion of adjacent leaflets, opening and eventually dilation of the fusion pore $[17,18]$. Membrane fusion can occur independently from the a protein TMD in the case of VAMP2, however, detailed analysis of the different stages of membrane fusion has shown that efficient fusion clearly requires the TMD [15, 16, 19-21] (for detailed discussion see recent reviews [7, 22-24]). Recent data from our and other laboratories have shown that its role may relate to the opening, expansion and stability of the fusion pore itself $[16,25,26]$. In structural terms the VAMP2 TMD is endowed with several unusual features: a high percentage of $\mathrm{C}_{\beta}$-branched hydrophobic amino acids (isoleucine, valine) [14] and consecutively a high amount of $\beta$-sheets $[12,13,25,27]$. Moreover, the ratio between $\alpha$ helices and $\beta$-sheets changes reversibly depending on peptide/lipid ratios in DOPC membranes with a preponderance of $\beta$-sheets at high protein concentrations $[12,13,25]$. Such high local concentrations of VAMP2 are expected to occur during membrane fusion as a 
synaptic vesicle contains some 70 copies of this protein [28] and their crowding is essential for fusion [29]. We do not know whether such an unusual and reversible structural conversion from $\alpha$-helices to $\beta$-sheets occurs in native cell membranes, but it clearly reflects a unique structural mobility of the VAMP2 TMD.

Synthetic transmembrane peptides containing only LV repeats are highly mobile and are fusogenic in artificial systems [30]. The current view holds that such a mobility of the transmembrane domain is crucial for membrane fusion [25, 26, 31]. It is intriguing that their activity is further enhanced by inserting a small amino acid glycine in the middle of the sequence $[32,33]$. VAMP isoforms involved in exocytosis contain at least two small amino acids in a central position $\left(\mathrm{G}_{100}\right.$ and $\mathrm{C}_{103}$ in VAMP2). These may confer a mobile kink linking the $\mathrm{N}$ - and C-terminal halves of the TMD $[32,34,35]$. We have shown previously that the point mutation of $\mathrm{G}_{100}$ and $\mathrm{C}_{103}$ to valines retards and shortens fusion pore opening in live cells [25].

Exocytotic vesicles contain a high amount of cholesterol [28] and this lipid is required for efficient membrane fusion in synthetic or cellular systems [36-38] although the precise step involved is still a matter of debate [39]. In the same vein charged phospholipids such as phosphatidylserine are relevant in membrane fusion [40]. Up to now, structural data on VAMP2 TMDs have been obtained in the absence of lipids [41], on proteins embedded in dehydrated membranes [11] or membranes containing only phosphatidylcholine [25], in detergent micelles or complex lipid bilayers albeit at low protein/lipid ratios of 1/200-300 [35, 42, 43] or using a charge restrained and shortened TMD in phosphatidylcholine/phosphatidylserine bilayers [27] (for detailed discussion see Hastoy et al. [7] ). We therefore addressed the effect of phosphatidylserine and cholesterol on the structural properties of the full-length VAMP2 TMD. Vibrational spectroscopy allows label-free simultaneous detection of the orientation and structural conformation of peptides and lipids [44]. We used these methods were used to address numerous issues pertinent to membrane rearrangement or fusion in model systems, improving considerably our understanding of viral membrane fusion proteins [45]. We have previously demonstrated the reversible structural mobility of VAMP2 TMDs in DOPC using either synthetic peptides or recombinant full-length proteins $[12,13,25]$. We have now used attenuated total reflection-FTIR (ATR-FTIR) spectroscopy to examine the structure wild-type VAMP2 TMDs (VAMP2 ${ }_{\mathrm{TM} 22}$ ) in various lipid compositions and peptide/lipid ratios. We have additionally taken advantage of biologically well characterized mutations in the central small residues 
$\left(\mathrm{G}_{100}, \mathrm{C}_{103} ; \mathrm{VAMP} 2_{\mathrm{TM} 22} \mathrm{VV}\right)$ that impede fusion pore opening and stability [25] and compared them to wild-type VAMP2 $2_{\mathrm{TM} 22}$.

\section{Material and methods}

\subsection{Peptides and lipids}

The transmembrane segment of the SNARE protein VAMP2, VAMP2 ${ }_{\mathrm{TM} 22}$, (MMIILGVICAIILIIIIVYFST) and its VV mutant VAMP2 $2_{\mathrm{TM} 22} \mathrm{VV}$ (MMIILVVIVAIILIIIIVYFST) were synthesized in-house (Applied Biosystems Synthesizer 433A, PE Biosystem, Courtaboeuf, France). HPLC could not be used for purification of the peptides as they are very hydrophobic and only soluble in 1,1,1,3,3,3-hexafluoroisopropanol (HFIP), therefore they were purified by several rounds of precipitation in butanol. The purity of the samples was estimated at over $98 \%$ according to mass spectrometry. MALDI-MS (Matrix-Assisted Laser Desorption Ionization Mass Spectrometry) analysis was performed on a MALDI-TOF-TOF (Ultraflex III, Bruker Daltonics, Bremen, Germany). VAMP2 ${ }_{\mathrm{TM} 22}$ and VAMP $2_{\mathrm{TM} 22} \mathrm{VV}$ were dissolved in HFIP at a final concentration of around $10 \mu \mathrm{M}$ for MS analysis. Samples were prepared with a thin layer method: the peptide solution was deposited on a thin layer of matrix crystals (alpha-cyano-4-hydroxycinnamic acid prepared in acetone) on the MALDI plate. The peaks at $\mathrm{m} / \mathrm{z} 2474.45$ and $\mathrm{m} / \mathrm{z} 2512.41$ observed on the MALDI spectra could be assigned to the $[\mathrm{M}+\mathrm{Na}]^{+}$adduct ion of the peptides VAMP $2_{\mathrm{TM} 22}$ and VAMP $2_{\mathrm{TM} 22} \mathrm{VV}$, respectively. These experimental masses were in agreement with the theoretical values: $\mathrm{m} / \mathrm{z} 2474.42$ and $\mathrm{m} / \mathrm{z} 2512.53$.

1,2-dimyristoyl-sn-glycero-3-phophatidylcholine (DMPC, CAS 8194-24-6), 1,2-dioleoyl-snglycero-3-phosphocholine (DOPC, CAS 4235-95-4), 1,2-dioleoyl-sn-glycero-3-phosphoserine (DOPS, CAS 90693-88-2) and cholesterol (CAS 57-88-5) were obtained from Sigma-Aldrich, France.

\subsection{ATR spectroscopy of multibilayers}

Stock solutions of phospholipids in chloroform were mixed with peptides (in hexafluoroisopropanol), followed by vortexing and stirring for $10 \mathrm{~min}$. Solvents were removed by rotatory evaporation vacuum pump and $\mathrm{D}_{2} \mathrm{O}$ was added for rehydration of the pure lipid or VAMP $2_{\mathrm{TM} 22} /$ lipid mixture. Hydration ratios were higher than $70 \%$. Multibilayers used for 
ATR spectroscopy were obtained by shearing a pure lipid or mixed VAMP $2_{\text {TM22 }} /$ lipid gels on the diamond ATR crystal surface (Golden gate, Eurolabo, Paris, France) with a Teflon stick [46]. ATR spectra of multibilayers [47-50] were recorded with a Nexus 670 equipped with a MCT detector cooled at $77 \mathrm{~K}$. Generally, 600 scans were co-added at a resolution of $8 \mathrm{~cm}^{-1}$, and a two-level zero-filling was performed. The amide I band was decomposed into individual bands characteristic of each secondary structure element using 6 components at 1620, 1630, 1640, 1655, 1670 and $1685 \mathrm{~cm}^{-1}$ (data not shown). This decomposition was performed with Peaksolve software (Version 5.0, GRAMS) and analyzed as a sum of Gaussian/Lorentzian curves, with a consecutive optimization of amplitudes, band positions and half-width of individual bands. Individual amide I band components are assigned to various peptide secondary structures on the basis of a large body of experimental data [48]. To determine the percentage of each secondary structure, deconvolution analysis was performed on the summation signal of the two polarization spectra to avoid the orientation effect of each secondary structure. 


\section{Results}

2.1. Polarized ATR study of VAMP2 ${ }_{\text {TM22 }}$ alone or inserted into neutral and negatively charged lipid multibilayers

We have previously demonstrated a reversible transition between $\alpha$-helices to $\beta$-sheets in lipid bilayers using a peptide corresponding to the transmembrane domain of the VAMP
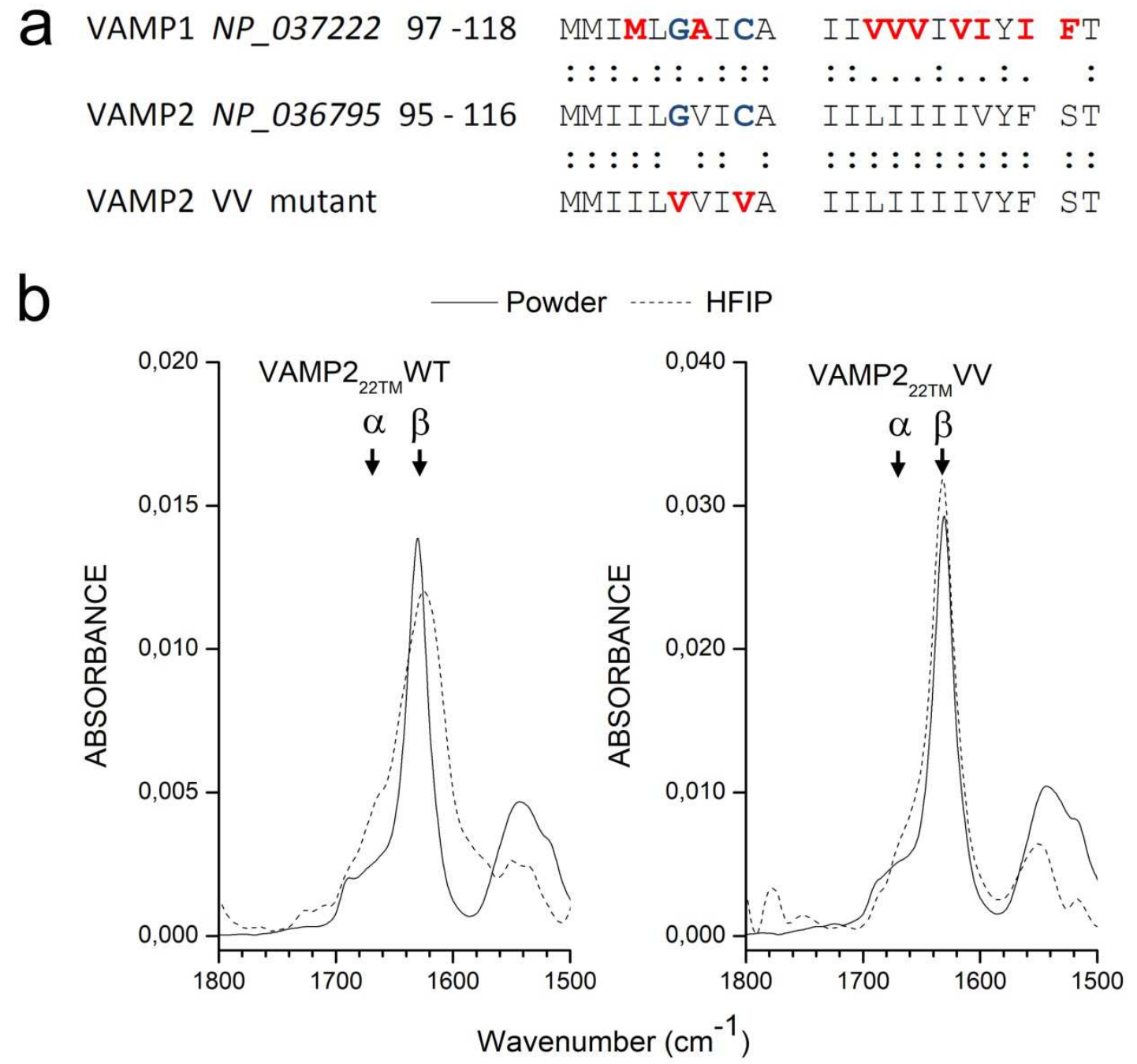

Figure 1: Sequences of wild-type VAMP1 or VAMP2 and mutated VAMP2 transmembrane domain (VAMP2 ${ }_{\mathrm{TM} 22}$ ). a: Sequence comparison of VAMP1 and VAMP2 transmembrane domains and VAMP2 mutant peptide. Note the preservation of small amino acids at $\mathrm{G}_{100}$ and $\mathrm{C}_{103}$ in both isoforms (given in blue), whereas exchanges are given in red (upper two sequences) and are mostly conservative ones among $\beta$-branched amino acids. The $\mathrm{G}_{100} \mathrm{~V}$ and $\mathrm{C}_{103} \mathrm{~V}$ mutation is given in red (lower sequence, VAMP2 VV mutant). b: ATR-IR spectra on a Ge crystal of the VAMP2 $2_{\mathrm{TM} 22}$ wild type and VAMP $2_{\mathrm{TM} 22} \mathrm{VV}\left(\mathrm{G}_{100} \mathrm{~V} / \mathrm{C}_{103} \mathrm{~V}\right)$ at room temperature. Both are mainly structured into antiparallel $\beta$-sheets as dry powder (solid line) or when dissolved in HFIP (dashed line). 
isoform VAMP1 $[12,13]$. The isoform VAMP2, involved in neurotransmission and peptide hormone secretion, differs within the TMD by 36\% from VAMP1 (9 of 22 amino acids, see Fig 1a) but contains a similar amount of $\mathrm{C}_{\beta}$-branched residues. The $\mathrm{G}_{100} \mathrm{~V} / \mathrm{C}_{103} \mathrm{~V}$ mutant abolishes the presence of central small residues and increases the overall $\mathrm{C}_{\beta}$-branched content (Fig. 1a). and rigidifies this region without significance increase in the local bulkiness [51]. We performed first ATR-FTIR experiments to provide quantitative data on the structure of VAMP2 TMD peptides (VAMP2 ${ }_{\text {TM22 }}$ ) in the absence of lipids. The wild-type or the $\mathrm{G}_{100} \mathrm{~V} / \mathrm{C}_{103} \mathrm{~V}$ (VV) mutant peptides were used as dry powder or dissolved in HFIP (Fig. 1b). Under both conditions, wild-type and VV peptides are mainly structured into anti-parallel $\beta$ sheets similar to VAMP1 [12].

Next VAMP2 $2_{\mathrm{TM} 22}$ was inserted into lipid bilayers composed either of DOPC or DOPC/DOPS with different peptide to lipid ratios. Note that these bilayers form stacks of multiple layers which enhance the signal. The polarized ATR spectra presented in the 1800$1550 \mathrm{~cm}^{-1}$ domain for wild-type and mutant VAMP2 ${ }_{\mathrm{TM} 22}$ in DOPC bilayers (Fig. 2a) show the $v(C=O)$ ester band of the lipid at a wavenumber of approximately $1735 \mathrm{~cm}^{-1}$ and the amide I

band characteristic of the VAMP $2_{\mathrm{TM} 22}$ between 1600 and $1700 \mathrm{~cm}^{-1}$. The amide I band mainly reflects $\mathrm{C}=\mathrm{O}$ as well as $\mathrm{C}-\mathrm{N}$ stretching vibrations, which are modulated by the peptide backbone conformation such $\alpha$-helices (around $1652 \mathrm{~cm}^{-1}$ ) or $\beta$-sheets (around $1630 \mathrm{~cm}^{-1}$ ). At the molecular ratio of $1 / 300$ (peptides/DOPC), mainly $\alpha$-helices (56\% of observed structures) and only a small amount of anti-parallel $\beta$-sheets were observed (7\%). The percentages of $\alpha$ helix and $\beta$-sheets structures in VAMP $2_{\mathrm{TM} 22}$ inserted into lipid multibilayers at different peptide/lipid ratio are presented in supplemental data (Table S1) after the deconvolution of the amide I band. As the wild type peptide/lipid ratio was increased, amide I/I' bands at around 1630/1685 $\mathrm{cm}^{-1}$ increased progressively (Fig. 2a), characteristic of anti-parallel $\beta$-sheets [52]. At the highest ratio tested $(1 / 20), \beta$-sheets became the predominant structure with the presence of residual $\alpha$-helical structure in DOPC bilayers as seen by a small peak at around $1655 \mathrm{~cm}^{-1}$ (Fig. 2a). For a more precise view of the $\alpha$-helix/ $\beta$-sheet region of the spectra at 1/300 peptide/lipid ratios, see supplemental Figure S1. The concentration dependent variation of structures in DOPC lipid membranes is similar to our previous finding with the transmembrane domain peptide VAMP1 $1_{\mathrm{TM} 22}$ or full-length VAMP1 $[12,13]$. Note that the use of TMD peptides implies the loss of directional information due to the absence of the soluble domain. However, we had shown for the isoform VAMP1 that $\beta$-sheets are mainly 
antiparallel when using the TMD only, but parallel when investigating the full-length peptide $[12,13]$.
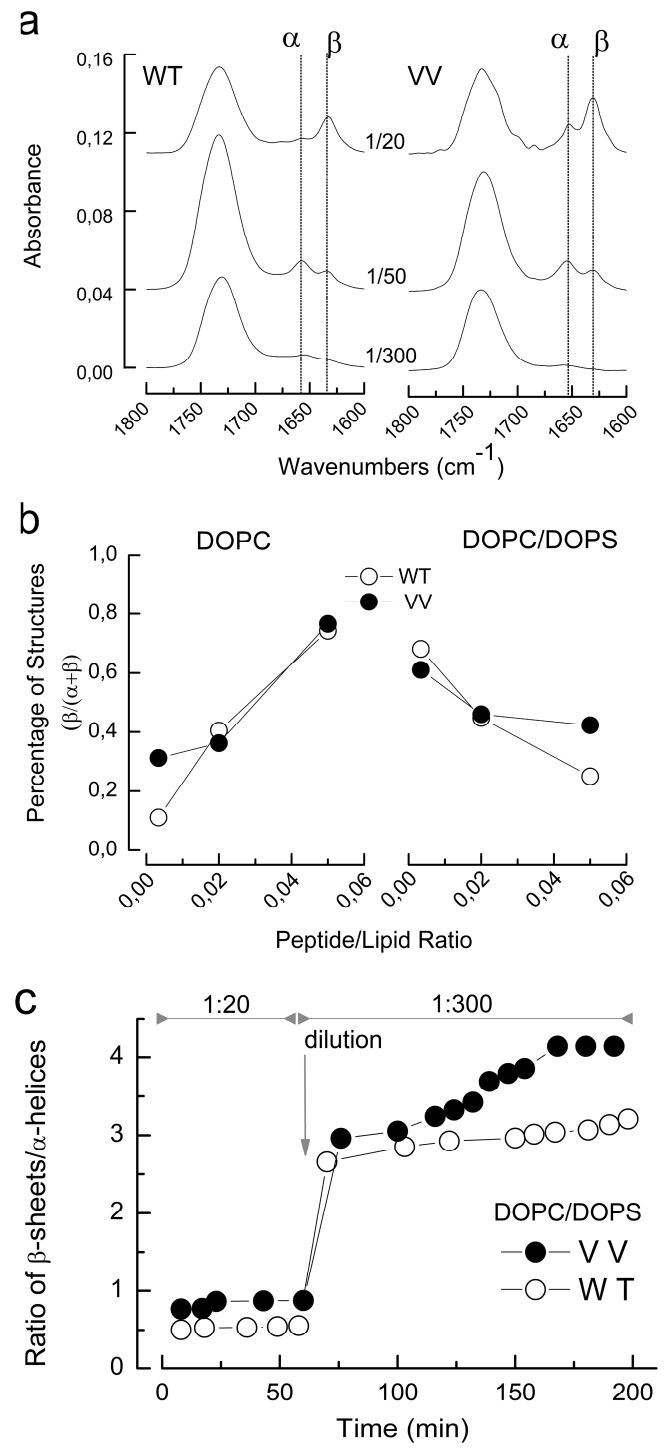

Figure 2: Lipid composition-dependent conformation of the transmembrane domain of VAMP2. a: ATR spectra on diamond crystal of VAMP $2_{\mathrm{TM} 22}$ (WT or VV mutant) inserted into DOPC multibilayers hydrated by $\mathrm{D}_{2} \mathrm{O}$ at a peptide/lipid ratio of 1/300, 1/50 or 1/20. Each spectrum resulted from the summation of the two polarization spectra (parallel (p) and perpendicular (s)). For detailed view of $\alpha$-helix and $\beta$-sheet regions at $1 / 300$, see supplemental figure S1. b: relative percentage of $\beta$-sheets structure of VAMP2 $2_{\mathrm{TM} 22}$ inserted into different lipid compositions DOPC or DOPC/DOPS (93/7 mol\%) multibilayers as obtained from ATR spectra. Wild-type $\bigcirc$, VV mutant 0 . c: Kinetics of structural dynamics in DOPC/DOPS bilayers. ATR-IR spectra of the synthetic peptide VAMP2 ${ }_{\mathrm{TM} 22}$ (either WT or VV mutant) in a lipid multi-bilayer (DOPC/DOPS, 93/7 mol\%) were obtained at an initial peptide/lipid ratio of $1 / 20$ at room temperature. After approximately $1 \mathrm{~h}$ peptides were diluted with DOPC/DOPS to a peptide/lipid ratio of $1 / 300$ (indicated by arrow) and structural changes measured for $3 \mathrm{~h}$ at room temperature. The ratios of intensities of $\beta$-sheets vs $\alpha-$ helices are given. $\mathrm{N}=3$, note that $\mathrm{SD}$ does not exceed symbol size. 
$\mathrm{VAMP}_{\mathrm{TM} 22} \mathrm{VV}$ peptides incorporated in DOPC are also predominantly structured as anti-parallel $\beta$-sheets at high peptide/lipid concentration $(1 / 20)$. This proportion decreases with decreasing peptide/lipid concentration, similarly as observed with wild type peptides (Fig. 2a and b, Table S1). However, the proportion of $\alpha$-helical structure is globally lower as compared to wild-type peptides. Using the shorter phosphatidylcholine DMPC instead of DOPC comparable effects were observed for both peptides in terms of peptide/lipid ratio dependent changes in structure (data not shown).

The effect of negative charges of the lipid membrane on the structure of VAMP $2_{\mathrm{TM} 22}$ was investigated using DOPC/DOPS lipid bilayers. Typically, cell membranes contain 5 to $15 \%$ of negatively charged lipids in their cytoplasmic leaflets, mostly as phosphatidylserine [53]. This lipid plays a complex role in exocytosis [54]. Its charge serves as anchorage for proteins implicated in membrane fusion and its regulation, but also favors positive curvatures of membranes or dimpling largely due to electrostatic interactions of the charged head groups [55]. In the present system, surprisingly, we observed that the addition of only $7 \%$ of negatively charged DOPS to the neutral DOPC membranes totally inversed the structural behavior of VAMP2 $2_{\mathrm{TM} 22}$ (Fig. 2b). At a 1/300 peptide/lipid ratio, 53\% of the peptide formed anti-parallel $\beta$-sheets and $23 \%$ was $\alpha$-helices whereas at a much higher peptide ratio, i.e. $1 / 20$, $\alpha$-helices were predominant (51\% vs $21 \%$ for $\beta$-sheets) (see Table S1). In the case of mutant VAMP $2_{\text {TM22 }}, \beta$-sheets were preponderant at a $1 / 300$ peptide/lipid ratio and converted to $\alpha$ helices at high peptide/lipid ratio (1/20). Thus a trend similar to the wild-type peptides was observed, but with higher proportion of $\beta$-sheets $(+12 \%)$ at the expense of $\alpha$-helical structure (-11\%) at the highest peptide/lipid ratio (1/20) (Fig 2b, Table S1).

We also investigated the reversibility and the kinetics of the structural changes of these peptides as we have previously reported for VAMP2 ${ }_{\mathrm{TM} 22}$ in DOPC membranes [25]. Similarly to those studies, the dilution of the peptide/lipid membranes (from 1/20 to 1/300) by further addition of lipids demonstrated the structural reversibility at room temperature (Fig. 2c). The kinetics of structure transition revealed that the structure transition of VAMP $2_{\mathrm{TM} 22} \mathrm{VV}$ in DOPC/DOPS lipid bilayers occurs in two steps whereas the transition of VAMP $2_{\text {TM} 22}$ WT occurs in one step: an initial rapid one that was common for both wildtype and VV mutated VAMP2 $2_{\mathrm{TM} 22}$ and a second less pronounced one starting approximately 60 minutes after the dilution that was only observed for VAMP $2_{\mathrm{TM} 22} \mathrm{VV}$. This latter one may reflect the increased content in $\mathrm{C}_{\beta}$-branched amino acids in VAMP $2_{\mathrm{TM} 22} \mathrm{VV}$ that further 
favors the presence of $\beta$-sheets.

\subsection{Effect of Cholesterol on the structures of VAMP2 ${ }_{\text {TM22 }}$}

Cholesterol is a major component of the plasma and the vesicle membranes [56]. Lipid analysis revealed a high cholesterol content of synaptic vesicles, constituting $45 \mathrm{~mol} \%$ of the total lipids [28] and cholesterol may influence vesicle fusion [36]. We assessed the effect of high cholesterol content in the multibilayers on the conformation of the SNARE TMDs and analyzed two lipid mixtures at increasing molecular percentages of cholesterol, consisting of either 73/7/20 or 49/7/44 DOPC/DOPS/Cholesterol molecular ratios.

The addition of $20 \%$ cholesterol to the lipid mixture totally suppressed the variation

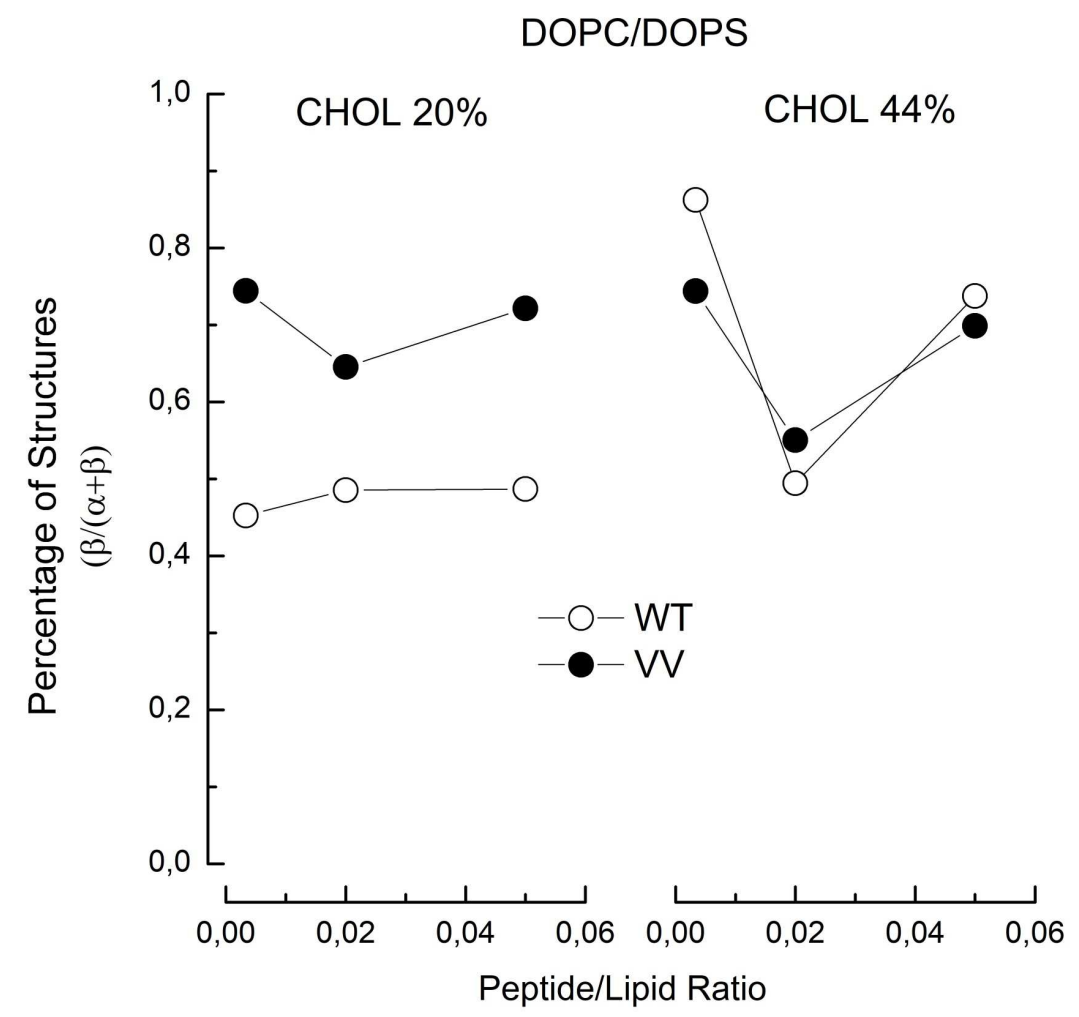

Figure 3: Cholesterol-dependent conformation of the transmembrane domain of VAMP2. Relative percentage of $\beta$-sheets structure of VAMP $2_{\mathrm{TM} 22}$ inserted into DOPC/DOPS multibilayers containing different either 20\% cholesterol (DOPC/DOPS 73/7 mol\%) or $44 \%$ cholesterol (DOPC/DOPS 49/7 mol\%) as obtained from ATR spectra. $\mathrm{N}=3$, note that SD does not exceed symbols size.

of the $\alpha$-helix and $\beta$-sheets in VAMP $2_{\mathrm{TM} 22}$, and the structure of the peptide remains intermediate and unchanged ( $40 \%$ for $\alpha$ or $\beta$ ) at all peptide/lipid ratios tested. A further 
increase of cholesterol content to $44 \%$, anti-parallel $\beta$-sheet becomes the dominant secondary structure ( 60-70\%) except at the intermediate ratio, 1/50 ( 45\%) (see Fig 3 and Table S1). Globally, our data clearly demonstrated that cholesterol plays a role in decreasing the variation of the secondary structures and maintaining them at a relatively high anti-parallel $\beta$ sheets regardless of the peptide to lipid ratio.

The addition of cholesterol to DOPC/DOPS multibilayers reduced the variations of the secondary structures of VAMP $2_{\mathrm{TM} 22} \mathrm{VV}$ similar to their effects on the wild type VAMP2 peptide. A higher overall percentage of $\beta$-sheets was observed for VAMP $2_{\mathrm{TM} 22} \mathrm{VV}$ with respect to the wild type peptides at $20 \%$ cholesterol whereas differences disappeared at $44 \%$ cholesterol (see Fig 3 and Table S1). Compared to DOPC/DOPS alone, cholesterol increased the presence of $\beta$-structures throughout the different ratios tested.

\subsection{Lipid chains perturbations induced by the inclusion of peptides}

Membrane fusion as in exocytosis imposes tight constraints on lipid acyl chain organisation [7]. We therefore addressed the effect of lipids and of lipid/peptide interactions on the properties of the membranes in terms of acyl chain organization (Fig. 4 and Tables S2). To this end, we evaluated the consequence of peptide insertion on the organization of the lipid multibilayers via the evolution of the frequencies of the antisymmetric and symmetric stretching modes of methylene groups, $v_{\mathrm{s}}\left(\mathrm{CH}_{2}\right)$ and $\mathrm{v}_{\mathrm{as}}\left(\mathrm{CH}_{2}\right)$ (Table S2). Indeed, the frequencies of these bands are known to be sensitive to changes in the configuration of the acyl chains, in chain mobility and packing. In the absence of peptides, the DOPC bilayers show the highest proportion of trans conformations of the acyl chains $\left(\mathrm{v}_{\mathrm{as}}\left(\mathrm{CH}_{2}\right)=2921.2 \mathrm{~cm}^{-1}\right.$, $\left.v_{\mathrm{s}}\left(\mathrm{CH}_{2}\right)=2851.7 \mathrm{~cm}^{-1}\right)$. The organization of the lipids decreases significantly both in the presence of DOPS or cholesterol and in the presence of peptides (both wild type and mutant VAMP2 $2_{\text {TM22 }}$ ), even at low peptide content (1/300 peptide/lipid ratio). These results further corroborated the analysis of the dichroic ratio $\left(\mathrm{R}_{\mathrm{ATR}}\right)$ of the $\mathrm{v}_{\mathrm{s}}\left(\mathrm{CH}_{2}-2853 \mathrm{~cm}^{-1}\right)$ band of DOPC lipid chains measured with the polarized ATR spectra (see Fig. 4). Multibilayers containing only DOPC are well organized, $\left(\mathrm{R}_{\mathrm{ATR}}=1.4\right.$ in average $)$. When VAMP $2_{\mathrm{TM} 22}$ or mutants peptides are inserted in multibilayers, the observed dichroic ratio $\left(R_{A T R}\right)$ of the $v_{S}$ $\left(\mathrm{CH}_{2}-2853 \mathrm{~cm}^{-1}\right)$ band strongly increased confirming the disorganization of lipids. Whereas there was no appreciable difference between wild-type and mutant VAMP $2_{\text {TM22 }}$ in DOPC, the mutant clearly induced a stronger effect in the presence of DOPS and especially upon further 


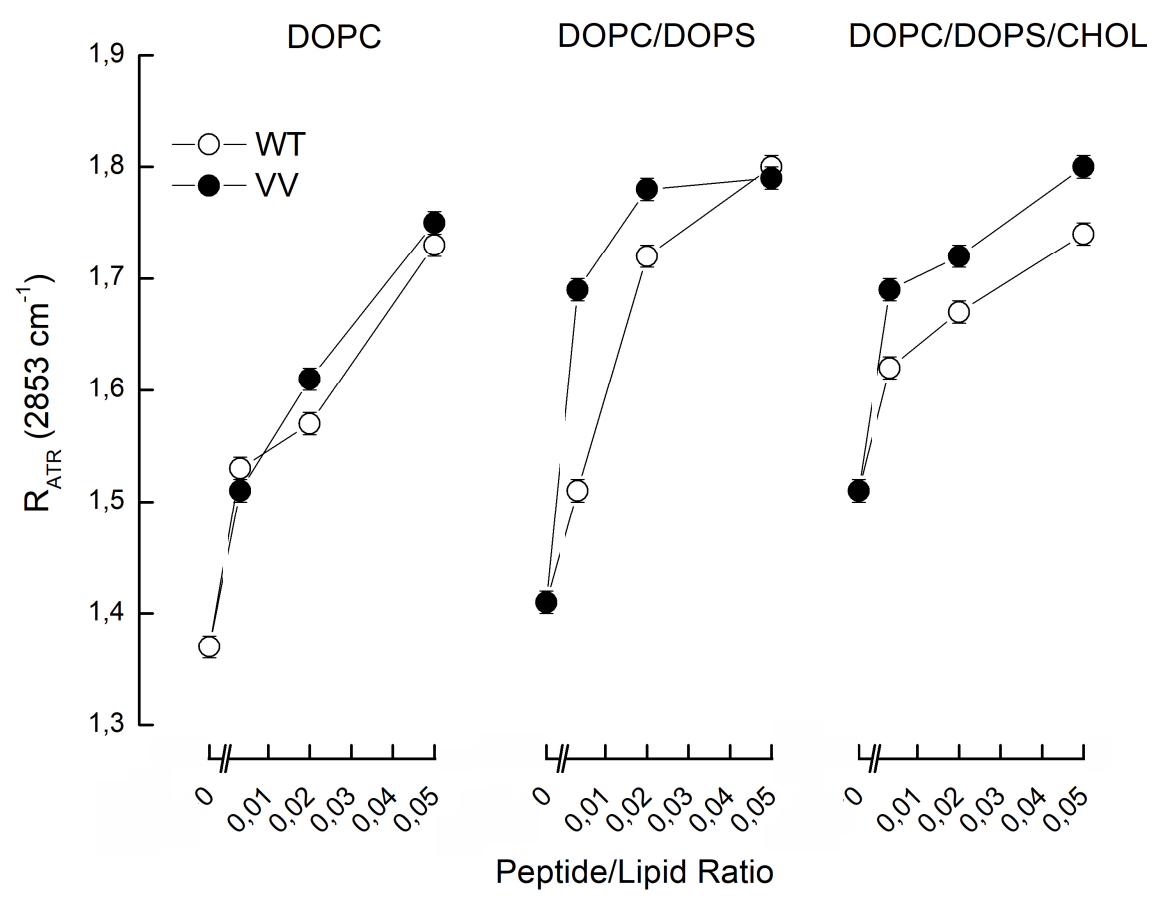

Figure 4: Effect of VAMP $\mathrm{TM}_{\mathrm{TM} 2}$ wt or mutant on lipid acyl chain alignment. Dichroic ratio $\left(\mathrm{R}_{\text {ATR }}\right)$ of the $v_{\mathrm{S}}\left(\mathrm{CH}_{2}-2853 \mathrm{~cm}^{-1}\right)$ band of lipid acyl chains were determined with VAMP2 $2_{\mathrm{TM} 22}$ wild type or $\mathrm{VAMP} 2_{\mathrm{TM} 22} \mathrm{VV}$ mutant peptides in various multibilayers at different molar peptide/lipid ratios employed. Note that an increase in $\mathrm{R}_{\mathrm{ATR}}$ of the $v_{\mathrm{S}}\left(\mathrm{CH}_{2^{-}}\right.$ $2853 \mathrm{~cm}^{-1}$ ) band indicates a decrease in the molecular ordering of acyl chains. Composition of multibilayers (in molecular percentages): a: DOPC, b: DOPC/DOPS (93/7 mol\%), c: DOPC/DOPS/Chol (49/7/44 mol\%). N=3, note that SD does often not exceed symbol size.

addition of cholesterol (Fig. 4). Note that these perturbations of the lipid chain organization also clearly demonstrate the interaction of the peptides with the hydrophobic portion of the bilayers even at high $\mathrm{R}_{\mathrm{i}}$ and are indicative of the insertion of the peptides into the bilayer. 


\section{Discussion}

Our observations indicate that the structure of the transmembrane domain of VAMP2 exhibits a strong sensitivity to local protein concentration and to specific lipid environments when incorporated into lipid bilayers. Most of our previously published results had been obtained using full-length or a TMD peptide of the isoform VAMP1 [12, 13], but clearly VAMP2 behaves similarly in DOPC. Although 9 out of the 22 residues of the TMD differ, most are conservative exchanges and the overall content in $\mathrm{C}_{\beta}$-branched amino acids, a hall mark of SNARE proteins TMDs, is conserved. The dependence of reversible $\alpha$-helices vs. $\beta$ sheets occurrence on peptide/lipid ratios in DOPC also applies to the full-length VAMP2 as shown recently by us [25] and does therefore not present an artefact due to truncation of the protein. Moreover, as shown here, reversibility is observed not only in DOPC but also in DOPC/DOPS. Although we cannot exclude a role of the juxtamembrane domain or the cytosolic portion in membranes containing DOPS and/or cholesterol, molecular dynamics suggest that the juxtamembrane domain contributes only little to the behavior of the TMD [57].

The pronounced effect of a small percentage of charged lipid head groups, as in the case of DOPS, on the hydrophobic membrane peptides VAMP2 $2_{\mathrm{TM} 22}$ is striking. DOPS, used here at a physiological concentration range, is sufficient to change the surface potential [58]. This lipid is required for SNARE protein-mediated vesicle fusion. Indeed, DOPS is thought to interact with charged residues of the VAMP juxtamembrane domain and may be involved during the hemifusion as well as the pore formation steps [40]. However, the peptides used here contain only the TMD without the juxtamembrane domain of VAMP2 and thus no charges are present in the peptide which may stabilize the TMD [59]. DOPS is characterized by a relatively rigid headgroup structure as compared with DOPC [60]. Globally, it stiffens lipid bilayers, alters lateral pressure profiles and may promote membrane curvature [61]. Especially the latter characteristic may also play a role in membrane deformation during fusion. Although we do not have any ready molecular explanation for the dramatic effect of DOPS on the structure of the TMD, our data clearly indicate an exquisite sensitivity to lipid headgroups that has not been observed previously for any other TMD. Notably, even in this setting VAMP2 TMD structure conserves its dependency on peptide/lipid ratios although the effect is completely inversed. 
Membranes containing only DOPC and DOPS are poorly fusogenic and further components such as cholesterol are required [62]. Cholesterol is required throughout exocytosis during hemifusion, fusion pore opening and its expansion [36, 63] although yeastderived vesicle fusion assays suggest mainly a role at earlier steps such as docking [39] . It contains a rigid ring structures that disrupts local packing order [64, 65] which is in perfect agreement with our observation (Fig 4 and table S2). It also favors bending of the lipid bilayer [66] and increases membrane thickness [67]. The latter effect does not differ between 20 and $44 \%$ cholesterol in DOPC/cholesterol bilayers [68] but the concentration dependency in DOPC/DOPS membranes is unknown. Both, plasma membrane and exocytotic vesicles are rich in cholesterol, however, this lipid seems to be required mainly in the vesicle membrane $[43,69]$.

Addition of cholesterol restored the preponderance of $\beta$-sheet structures. Notably, an increase in cholesterol concentration from 20 to $44 \%$ further increased the overall the percentage of $\beta$-sheets, clearly demonstrating a specific and concentration dependent effect. Detailed fine analysis of cholesterol effects on membrane fusion and pore opening in cell assays and proteoliposome fusion indicated a role for this lipid beyond membrane bending and it was suggested that it may directly alter the conformation of the VAMP TMD [43, 64, 69]. We may therefor hypothesize that the change in structures observed here may correlate at least in part with a cholesterol effect on the TMD function observed in the aforementioned assays.

Clearly we did not observe an influence of the peptide/lipid ratio in the presence of cholesterol as compared to the effects observed here for DOPC or DOPC/DOPS or in our previously published experiments $[12,13,25]$. A number of SNARE complexes are required for exocytosis at a physiological rate [70,71], although one or two may suffice to obtain fusion $[72,73]$. Indeed, the extent of fusion pore opening, expansion and stability in artificial membranes is exponentially enhanced by an increase in the number of SNARE complexes $[16,74,75]$. We previously argued that the presence of numerous copies of VAMP2 [28] and its further crowding of TMDs during fusion [29] may be a trigger for conformational changes. The absence of an effect through peptide/lipid ratios in the presence of cholesterol argues at first sight against such a phenomenon. However, theoretical considerations suggest that not only SNARE distributions may change during exocytosis, but also the distribution of lipid species, such as cholesterol, to obtain the membrane curvature required for initial hemifusion, stalk formation and fusion pore opening [7]. This issue has not yet been addressed 
experimentally due to inherent technical difficulties. In light of these requirements one may hypothesize that dynamic changes in TMDs still occur and are perhaps even mainly driven or stabilized by the changing lipid environment.

We have shown previously that the VAMP $2_{\mathrm{TM} 22}$ mutant $\left(\mathrm{G}_{100} \mathrm{~V} / \mathrm{C}_{103} \mathrm{~V}\right)$ reduces exocytosis by altering fusion pore opening and expansion in live cells [25]. These residues are probably situated close to the center of the bilayer as the preceding amphipathic juxtamembrane domain is already partially embedded in the membrane [34, 35]. Within the static assays performed here, the mutant behaved as wild-type VAMP $2_{\mathrm{TM} 22}$ in zwitterionic and anionic bilayers (DOPC, DOPC/DOPS) although some higher propensity for $\beta$-sheets was observed, in line with the additional presence of two $\mathrm{C}_{\beta}$-branched residues known to favor $\beta$-sheet conformation. Note that using a dynamic assay (and DOPC only) we have previously observed, a considerable delay and reduction in the structural conversions from $\alpha$ helices to $\beta$-sheets and back to $\alpha$-helices in the case of the VAMP $2_{\mathrm{TM} 22}$ mutant $\left(\mathrm{G}_{100} \mathrm{~V} / \mathrm{C}_{103} \mathrm{~V}\right)$ [25]. A major difference between wild-type and mutant was observed now in the presence of $20 \%$ cholesterol, i.e. a higher percentage of $\beta$-sheets in the case of mutant VAMP $2_{\mathrm{TM} 22}$, which was no longer apparent at $44 \%$ cholesterol. Some attention has to be paid to the physiological relevance of the two cholesterol concentrations used here. Although cholesterol accounts for some 40 to $60 \%$ of all the lipids in exocytotic vesicles $[28,76]$, almost half of the synaptic vesicle surface is occupied by transmembrane domains. In contrast, in our approach, we use only a single peptide which amount at most to $5 \%$ of the total peptide/lipid mixture. One may therefore assume that the total number of cholesterol molecules available for VAMP2 in situ in synaptic vesicles may be closer to the lower cholesterol concentration used in this study $(20 \%)$.

A further difference between wild-type and mutant was observed in terms of acyl-chain ordering. In DOPC/DOPS and in DOPC/DOPS/CHOL membranes the mutant induced a more pronounced disordering as compared to the wild-type peptides. Molecular simulations and structural studies indicated some unwinding around $\mathrm{G}_{100}$, which should result in an increased flexibility [11, 34]. Loss of this flexibility, as in the case of the mutant, may decrease adaptation of the peptide to the bilayer. Since during fusion and fusion pore opening the membrane is exposed to a number of constraints such as strong bending and high protein concentration, loss of flexibility in the mutant may contribute to its functional effects which we have reported recently [25]. 
In conclusion, the role of VAMP TMDs during the final stages of exocytosis has been established recently in cellular assays by us and others [25, 26]. Results presented here extend our previous observation on the general influence of protein/lipid ratios on the structure of VAMP TMDs to the strong role of the specific lipid environment. The reversible conversion from $\alpha$-helices to $\beta$-sheets is an in-vitro readout of the structural dynamics of VAMP2 TMD and may not happen to this extent in highly complex native cell membranes. However, more subtle qualities such as structural mobility and helical kink are clearly involved in physiological exocytosis $[25,26,34]$. The parameters measured here may reflect the capacity of the TMD to sense the dynamic lipid environment and to adapt to the different constraints during the fusion pore opening and dilation.

\section{Acknowledgments}

This work was supported by funds from the Agence National de Recherche (ANR) Programme «Physique et Chimie du Vivant» $(P C V-07)$ and a $\mathrm{PhD}$ grant from the French Ministry of Research.

\section{References}

[1] R. Jahn, D. Fasshauer, Molecular machines governing exocytosis of synaptic vesicles, Nature, 490 (2012) 201-207.

[2] D. Fasshauer, R.B. Sutton, A.T. Brunger, R. Jahn, Conserved structural features of the synaptic fusion complex: SNARE proteins reclassified as Q- and R-SNAREs, Proc Natl Acad Sci U S A, 95 (1998) 15781-15786.

[3] R.B. Sutton, D. Fasshauer, R. Jahn, A.T. Brunger, Crystal structure of a SNARE complex involved in synaptic exocytosis at 2.4 A resolution, Nature, 395 (1998) 347-353.

[4] T.C. Sudhof, J.E. Rothman, Membrane fusion: grappling with SNARE and SM proteins, Science, 323 (2009) 474-477.

[5] L.V. Chernomordik, J. Zimmerberg, M.M. Kozlov, Membranes of the world unite!, J Cell Biol, 175 (2006) 201-207.

[6] W.-D. Zhao, E. Hamid, W. Shin, P.J. Wen, E.S. Krystofiak, S.A. Villarreal, H.-C. Chiang, B. Kachar, L.-G. Wu, Hemi-fused structure mediates and controls fusion and fission in live cells, Nature, 534 (2016) 548-552. 
[7] B. Hastoy, A. Clark, P. Rorsman, J. Lang, Fusion pore in exocytosis: More than an exit gate? A beta-cell perspective, Cell Calcium, 68 (2017) 45-61.

[8] S. Ferro-Novick, R. Jahn, Vesicle fusion from yeast to man, Nature, 370 (1994) 191-193.

[9] R. Regazzi, C.B. Wollheim, J. Lang, J.M. Theler, O. Rossetto, C. Montecucco, K. Sadoul, U. Weller, M. Palmer, B. Thorens, VAMP-2 and cellubrevin are expressed in pancreatic beta-cells and are essential for $\mathrm{Ca}^{2+}$-but not for GTP $\gamma S$-induced insulin secretion, EMBO J, 14 (1995) 2723-2730.

[10] J.E. Rothman, The principle of membrane fusion in the cell (Nobel lecture), Angew Chem Int Ed Engl, 53 (2014) 12676-12694.

[11] M. Bowen, A.T. Brunger, Conformation of the synaptobrevin transmembrane domain, Proc Natl Acad Sci U S A, 103 (2006) 8378-8383.

[12] W. Yassine, N. Taib, S. Federman, A. Milochau, S. Castano, W. Sbi, C. Manigand, M. Laguerre, B. Desbat, R. Oda, J. Lang, Reversible transition between alpha-helix and betasheet conformation of a transmembrane domain, Biochim Biophys Acta, 1788 (2009) 1722-1730.

[13] W. Yassine, A. Milochau, S. Buchoux, J. Lang, B. Desbat, R. Oda, Effect of monolayer lipid charges on the structure and orientation of protein VAMP1 at the air-water interface, Biochim Biophys Acta, 1798 (2010) 928-937.

[14] D. Langosch, M. Hofmann, C. Ungermann, The role of transmembrane domains in membrane fusion, Cell Mol Life Sci, 64 (2007) 850-864.

[15] P. Zhou, T. Bacaj, X. Yang, Z.P. Pang, T.C. Sudhof, Lipid-anchored SNAREs lacking transmembrane regions fully support membrane fusion during neurotransmitter release, Neuron, 80 (2013) 470-483.

[16] L. Shi, Q.T. Shen, A. Kiel, J. Wang, H.W. Wang, T.J. Melia, J.E. Rothman, F. Pincet, SNARE proteins: one to fuse and three to keep the nascent fusion pore open, Science, 335 (2012) 1355-1359.

[17] J.R. Monck, G. Alvarez de Toledo, J.M. Fernandez, Tension in secretory granule membranes causes extensive membrane transfer through the exocytotic fusion pore, Proc Natl Acad Sci U S A, 87 (1990) 7804-7808.

[18] W. Shin, L. Ge, G. Arpino, S.A. Villarreal, E. Hamid, H. Liu, W.D. Zhao, P.J. Wen, H.C. Chiang, L.G. Wu, Visualization of Membrane Pore in Live Cells Reveals a DynamicPore Theory Governing Fusion and Endocytosis, Cell, 173 (2018) 934-945.e912. 
[19] C.W. Chang, E. Hui, J. Bai, D. Bruns, E.R. Chapman, M.B. Jackson, A structural role for the synaptobrevin 2 transmembrane domain in dense-core vesicle fusion pores, $\mathbf{J}$ Neurosci, 35 (2015) 5772-5780.

[20] C.W. Chang, C.W. Chiang, J.D. Gaffaney, E.R. Chapman, M.B. Jackson, Lipid-anchored Synaptobrevin Provides Little or No Support for Exocytosis or Liposome Fusion, J Biol Chem, 291 (2016) 2848-2857.

[21] J.D. Wehland, A.S. Lygina, P. Kumar, S. Guha, B.E. Hubrich, R. Jahn, U. Diederichsen, Role of the transmembrane domain in SNARE protein mediated membrane fusion: peptide nucleic acid/peptide model systems, Molecular bioSystems, 12 (2016) 27702776.

[22] E. Karatekin, Toward a unified picture of the exocytotic fusion pore, FEBS Lett, 592 (2018) 3563-3585.

[23] S. Sharma, M. Lindau, The fusion pore, 60 years after the first cartoon, FEBS Lett, 592 (2018) 3542-3562.

[24] Z. Wu, S. Thiyagarajan, B. O'Shaughnessy, E. Karatekin, Regulation of Exocytotic Fusion Pores by SNARE Protein Transmembrane Domains, Front Mol Neurosci, 10 (2017) 315.

[25] B. Hastoy, P.A. Scotti, A. Milochau, Z. Fezoua-Boubegtiten, J. Rodas, R. Megret, B. Desbat, M. Laguerre, S. Castano, D. Perrais, P. Rorsman, R. Oda, J. Lang, A central small amino acid in the vamp2 transmembrane domain regulates the fusion pore in exocytosis, Sci Rep, 7 (2017) 2835.

[26] M. Dhara, A. Yarzagaray, M. Makke, B. Schindeldecker, Y. Schwarz, A. Shaaban, S. Sharma, R.A. Bockmann, M. Lindau, R. Mohrmann, D. Bruns, v-SNARE transmembrane domains function as catalysts for vesicle fusion, Elife, 5 (2016)

[27] D. Langosch, J.M. Crane, B. Brosig, A. Hellwig, L.K. Tamm, J. Reed, Peptide mimics of SNARE transmembrane segments drive membrane fusion depending on their conformational plasticity, J Mol Biol, 311 (2001) 709-721.

[28] S. Takamori, M. Holt, K. Stenius, E.A. Lemke, M. Gronborg, D. Riedel, H. Urlaub, S. Schenck, B. Brugger, P. Ringler, S.A. Muller, B. Rammner, F. Grater, J.S. Hub, B.L. De Groot, G. Mieskes, Y. Moriyama, J. Klingauf, H. Grubmuller, J. Heuser, F. Wieland, R. Jahn, Molecular anatomy of a trafficking organelle, Cell, 127 (2006) 831-846. 
[29] Z. Wu, O.D. Bello, S. Thiyagarajan, S.M. Auclair, W. Vennekate, S.S. Krishnakumar, B. O'Shaughnessy, E. Karatekin, Dilation of fusion pores by crowding of SNARE proteins, Elife, 6 (2017)

[30] M.W. Hofmann, K. Weise, J. Ollesch, P. Agrawal, H. Stalz, W. Stelzer, F. Hulsbergen, H. de Groot, K. Gerwert, J. Reed, D. Langosch, De novo design of conformationally flexible transmembrane peptides driving membrane fusion, Proc Natl Acad Sci U S A, 101 (2004) 14776-14781.

[31] S. Sharma, M. Lindau, The fusion pore, 60 years after the first cartoon, FEBS Lett, (2018)

[32] P. Hogel, A. Gotz, F. Kuhne, M. Ebert, W. Stelzer, K.D. Rand, C. Scharnagl, D. Langosch, Glycine Perturbs Local and Global Conformational Flexibility of a Transmembrane Helix, Biochemistry, 57 (2018) 1326-1337.

[33] H.A. Scheidt, K. Kolocaj, J. Veje Kristensen, D. Huster, D. Langosch, Transmembrane Helix Induces Membrane Fusion through Lipid Binding and Splay, J Phys Chem Lett, 9 (2018) 3181-3186.

[34] A.E. Blanchard, M.J. Arcario, K. Schulten, E. Tajkhorshid, A highly tilted membrane configuration for the prefusion state of synaptobrevin, Biophys J, 107 (2014) 2112-2121.

[35] D.H. Kweon, C.S. Kim, Y.K. Shin, Regulation of neuronal SNARE assembly by the membrane, Nat Struct Biol, 10 (2003) 440-447.

[36] A. Tse, A.K. Lee, L. Yan, F.W. Tse, Influence of cholesterol on cellular signaling and fusion pore kinetics, J Mol Neurosci, 48 (2012) 395-401.

[37] N. Najafinobar, L.J. Mellander, M.E. Kurczy, J. Dunevall, T.B. Angerer, J.S. Fletcher, A.S. Cans, Cholesterol Alters the Dynamics of Release in Protein Independent Cell Models for Exocytosis, Sci Rep, 6 (2016) 33702.

[38] B.S. Stratton, J.M. Warner, Z. Wu, J. Nikolaus, G. Wei, E. Wagnon, D. Baddeley, E. Karatekin, B. O'Shaughnessy, Cholesterol Increases the Openness of SNARE-Mediated Flickering Fusion Pores, Biophys J, 110 (2016) 1538-1550.

[39] Y. Lai, L. Zhao, B. Bu, X. Lou, D. Li, B. Ji, J. Liu, J. Diao, Y.K. Shin, Lipid molecules influence early stages of yeast SNARE-mediated membrane fusion, Phys Biol, 12 (2015) 025003. 
[40] P.K. Tarafdar, H. Chakraborty, M.J. Bruno, B.R. Lentz, Phosphatidylserine-Dependent Catalysis of Stalk and Pore Formation by Synaptobrevin JMR-TMD Peptide, Biophys J, 109 (2015) 1863-1872.

[41] A. Stein, G. Weber, M.C. Wahl, R. Jahn, Helical extension of the neuronal SNARE complex into the membrane, Nature, 460 (2009) 525-528.

[42] J.F. Ellena, B. Liang, M. Wiktor, A. Stein, D.S. Cafiso, R. Jahn, L.K. Tamm, Dynamic structure of lipid-bound synaptobrevin suggests a nucleation-propagation mechanism for trans-SNARE complex formation, Proc Natl Acad Sci U S A, 106 (2009) 20306-20311.

[43] J. Tong, P.P. Borbat, J.H. Freed, Y.K. Shin, A scissors mechanism for stimulation of SNARE-mediated lipid mixing by cholesterol, Proc Natl Acad Sci U S A, 106 (2009) $5141-5146$.

[44] Z.D. Schultz, I.W. Levin, Vibrational spectroscopy of biomembranes, Annu Rev Anal Chem, 4 (2011) 343-366.

[45] Y. Shai, ATR-FTIR studies in pore forming and membrane induced fusion peptides, Biochim Biophys Acta, 1828 (2013) 2306-2313.

[46] W. Hubner, H.H. Mantsch, Orientation of specifically $13 \mathrm{C}=\mathrm{O}$ labeled phosphatidylcholine multilayers from polarized attenuated total reflection FT-IR spectroscopy, Biophys J, 59 (1991) 1261-1272.

[47] E. Goormaghtigh, V. Cabiaux, J.M. Ruysschaert, Secondary structure and dosage of soluble and membrane proteins by attenuated total reflection Fourier-transform infrared spectroscopy on hydrated films, Eur J Biochem, 193 (1990) 409-420.

[48] E. Goormaghtigh, V. Cabiaux, J.M. Ruysschaert, Determination of soluble and membrane protein structure by Fourier transform infrared spectroscopy., Sub-cell Biochem, 23 (1994) 329-450.

[49] E. Goormaghtigh, V. Raussens, J.M. Ruysschaert, Attenuated total reflection infrared spectroscopy of proteins and lipids in biological membranes, Biochim Biophys Acta, 1422 (1999) 105-185.

[50] U.P. Fringeli, In situ infrared attenuated total reflection membrane spectroscopy, in: F.M. Mirabella Jr. (Ed.) Internal Reflection Spectroscopy: Theory and Application., vol. 14, Marcel Dekker, New York, 1993, pp. 255-324. 
[51] M.J. Betts, R.B. Russell, Amino acid properties and consequences of subsitutions. , in: M.R. Barnes, I.C. I.C. Gray (Eds.) Bioinformatics for Geneticists., John Wiley \& Sons, New York, 2003.

[52] J. Bandekar, S. Krimm, Vibrational analysis of peptides, polypeptides, and proteins: Characteristic amide bands of beta-turns, Proc Natl Acad Sci U S A, 76 (1979) 774-777.

[53] M.J. MacDonald, L. Ade, J.M. Ntambi, I.-U.H. Ansari, S.W. Stoker, Characterization of phospholipids in insulin secretory granules and mitochondria in pancreatic beta cells and their changes with glucose stimulation, J Biol Chem, 290 (2015) 11075-11092.

[54] Z. Zhang, E. Hui, E.R. Chapman, M.B. Jackson, Phosphatidylserine regulation of $\mathrm{Ca}^{2+}$ triggered exocytosis and fusion pores in PC12 cells, Mol Biol Cell, 20 (2009) 5086-5095.

[55] N. Fuller, C.R. Benatti, R.P. Rand, Curvature and bending constants for phosphatidylserine-containing membranes, Biophys J, 85 (2003) 1667-1674.

[56] G. van Meer, D.R. Voelker, G.W. Feigenson, Membrane lipids: where they are and how they behave, Nature reviews. Molecular cell biology, 9 (2008) 112-124.

[57] J. Han, K. Pluhackova, T.A. Wassenaar, R.A. Bockmann, Synaptobrevin transmembrane domain dimerization studied by multiscale molecular dynamics simulations, Biophys J, 109 (2015) 760-771.

[58] C. Lütgebaucks, C. Macias-Romero, S. Roke, Characterization of the interface of binary mixed DOPC:DOPS liposomes in water: The impact of charge condensation, J Chem Phys, 146 (2017) 044701.

[59] K. Shahidullah, E. London, Effect of lipid composition on the topography of membraneassociated hydrophobic helices: stabilization of transmembrane topography by anionic lipids, J MolBiol, 379 (2008) 704-718.

[60] J.L. Browning, J. Seelig, Bilayers of phosphatidylserine: a deuterium and phosphorus nuclear magnetic resonance study, Biochemistry, 19 (1980) 1262-1270.

[61] J.J.L. Cascales, S.D.O. Costa, A. Garro, R.D. Enriz, Mechanical properties of binary DPPC/DPPS bilayers, RSC Adv, 2 (2012) 11743-11750.

[62] S.T. Yang, V. Kiessling, L.K. Tamm, Line tension at lipid phase boundaries as driving force for HIV fusion peptide-mediated fusion, Nat Commun, 7 (2016) 11401.

[63] S.T. Yang, A.J. Kreutzberger, J. Lee, V. Kiessling, L.K. Tamm, The role of cholesterol in membrane fusion, Chemistry and physics of lipids, 199 (2016) 136-143. 
[64] J. Chang, S.A. Kim, X. Lu, Z. Su, S.K. Kim, Y.K. Shin, Fusion step-specific influence of cholesterol on SNARE-mediated membrane fusion, Biophys J, 96 (2009) 1839-1846.

[65] H. Jin, J.M. McCaffery, E. Grote, Ergosterol promotes pheromone signaling and plasma membrane fusion in mating yeast, J Cell Biol, 180 (2008) 813-826.

[66] M.A. Churchward, T. Rogasevskaia, J. Hofgen, J. Bau, J.R. Coorssen, Cholesterol facilitates the native mechanism of $\mathrm{Ca}^{2+}$-triggered membrane fusion, J Cell Sci, 118 (2005) 4833-4848.

[67] J. Henriksen, A.C. Rowat, E. Brief, Y.W. Hsueh, J.L. Thewalt, M.J. Zuckermann, J.H. Ipsen, Universal behavior of membranes with sterols, Biophys J, 90 (2006) 1639-1649.

[68] Brett N. Olsen, Agata A. Bielska, T. Lee, Michael D. Daily, Douglas F. Covey, Paul H. Schlesinger, Nathan A. Baker, Daniel S. Ory, The structural basis of cholesterol accessibility in membranes, Biophys J, 105 (2013) 1838-1847.

[69] N. Wang, C. Kwan, X. Gong, E.P. de Chaves, A. Tse, F.W. Tse, Influence of cholesterol on catecholamine release from the fusion pore of large dense core chromaffin granules, $\mathbf{J}$ Neurosci, 30 (2010) 3904-3911.

[70] Y. Hua, R.H. Scheller, Three SNARE complexes cooperate to mediate membrane fusion, Proc Natl Acad Sci U S A, 98 (2001) 8065-8070.

[71] M.K. Domanska, V. Kiessling, L.K. Tamm, Docking and fast fusion of synaptobrevin vesicles depends on the lipid compositions of the vesicle and the acceptor SNARE complex-containing target membrane, Biophys J, 99 (2010) 2936-2946.

[72] G. van den Bogaart, M.G. Holt, G. Bunt, D. Riedel, F.S. Wouters, R. Jahn, One SNARE complex is sufficient for membrane fusion, Nat Struct Mol Biol, 17 (2010) 358-364.

[73] R. Sinha, S. Ahmed, R. Jahn, J. Klingauf, Two synaptobrevin molecules are sufficient for vesicle fusion in central nervous system synapses, Proc Natl Acad Sci U S A, 108 (2011) $14318-14323$.

[74] H. Mostafavi, S. Thiyagarajan, B.S. Stratton, E. Karatekin, J.M. Warner, J.E. Rothman, B. O'Shaughnessy, Entropic forces drive self-organization and membrane fusion by SNARE proteins, Proc Natl Acad Sci U S A, 114 (2017) 5455-5460.

[75] H. Bao, D. Das, N.A. Courtney, Y. Jiang, J.S. Briguglio, X. Lou, D. Roston, Q. Cui, B. Chanda, E.R. Chapman, Dynamics and number of trans-SNARE complexes determine nascent fusion pore properties, Nature, 554 (2018) 260-263. 
[76] S. Dhanvantari, Y.P. Loh, Lipid raft association of carboxypeptidase e is necessary for its function as a regulated secretory pathway sorting receptor, J Biol Chem, 275 (2000) 29887-29893. 


\section{FIGURE LEGENDS}

Figure 1: Sequences of wild-type VAMP1 or VAMP2 and mutated VAMP2 transmembrane domain (VAMP2 ${ }_{\mathrm{TM} 22}$ ). a: Sequence comparison of VAMP1 and VAMP2 transmembrane domains and VAMP2 mutant peptide. Note the preservation of small amino acids at $\mathrm{G}_{100}$ and $\mathrm{C}_{103}$ in both isoforms (given in blue), whereas exchanges are given in red (upper two sequences) and are mostly conservative ones among $\beta$-branched amino acids. The $\mathrm{G}_{100} \mathrm{~V}$ and $\mathrm{C}_{103} \mathrm{~V}$ mutation is given in red (lower sequence, VAMP2 VV mutant). b: ATR-IR spectra on a $\mathrm{Ge}$ crystal of the VAMP $2_{\mathrm{TM} 22}$ wild type and VAMP $2_{\mathrm{TM} 22} \mathrm{VV}\left(\mathrm{G}_{100} \mathrm{~V} / \mathrm{C}_{103} \mathrm{~V}\right)$ at room temperature. Both are mainly structured into anti-parallel $\beta$-sheets as dry powder (solid line) or when dissolved in HFIP (dashed line).

Figure 2: Lipid composition-dependent conformation of the transmembrane domain of VAMP2. a: ATR spectra on diamond crystal of VAMP2 $2_{\mathrm{TM} 22}$ (WT or VV mutant) inserted into DOPC multibilayers hydrated by $\mathrm{D}_{2} \mathrm{O}$ at a peptide/lipid ratio of 1/300, 1/50 or 1/20. Each spectrum resulted from the summation of the two polarization spectra (parallel (p) and perpendicular (s)). For detailed view of $\alpha$-helix and $\beta$-sheet regions at $1 / 300$, see supplemental figure $S 1$. b: relative percentage of $\beta$-sheets structure of VAMP $2_{\mathrm{TM} 22}$ inserted into different lipid compositions DOPC or DOPC/DOPS (93/7 mol\%) multibilayers as obtained from ATR spectra. Wild-type $\bigcirc$, VV mutant 0 . c: Kinetics of structural dynamics in DOPC/DOPS bilayers. ATR-IR spectra of the synthetic peptide VAMP2 ${ }_{\mathrm{TM} 22}$ (either WT or VV mutant) in a lipid multi-bilayer (DOPC/DOPS, 93/7 mol\%) were obtained at an initial peptide/lipid ratio of $1 / 20$ at room temperature. After approximately $1 \mathrm{~h}$ peptides were diluted with DOPC/DOPS to a peptide/lipid ratio of 1/300 (indicated by arrow) and structural changes measured for $3 \mathrm{~h}$ at room temperature. The ratios of intensities of $\beta$-sheets vs $\alpha$ helices are given. $\mathrm{N}=3$, note that $\mathrm{SD}$ does not exceed symbols size.

Figure 3: Cholesterol-dependent conformation of the transmembrane domain of VAMP2. Relative percentage of $\beta$-sheets structure of $\mathrm{VAMP} 2_{\mathrm{TM} 22}$ inserted into DOPC/DOPS multibilayers containing different either 20\% cholesterol (DOPC/DOPS 73/7 mol\%) or 44\% cholesterol (DOPC/DOPS 49/7 mol\%) as obtained from ATR spectra. N=3, note that SD does not exceed symbols size. 
Figure 4: Effect of $\mathrm{VAMP}_{\mathrm{TM} 22}$ wt or mutant on lipid acyl chain alignment. Dichroic ratio $\left(\mathrm{R}_{\mathrm{ATR}}\right)$ of the $\mathrm{v}_{\mathrm{s}}\left(\mathrm{CH}_{2}-2853 \mathrm{~cm}^{-1}\right)$ band of lipid acyl chains were determined with VAMP2 $2_{\mathrm{TM} 22}$ wild type or $\mathrm{VAMP} 2_{\mathrm{TM} 22} \mathrm{VV}$ mutant peptides in various multibilayers at different molar peptide/lipid ratios employed. Note that an increase in $\mathrm{R}_{\mathrm{ATR}}$ of the $\mathrm{v}_{\mathrm{S}}\left(\mathrm{CH}_{2}-2853 \mathrm{~cm}^{-1}\right)$ band indicates a decrease in the molecular ordering of acyl chains. Composition of multibilayers (in molecular percentages): a: DOPC, b: DOPC/DOPS (93/7 mol\%), c: DOPC/DOPS/Chol (49/7/44 mol\%). N=3, note that SD does often not exceed symbols size. 


\section{Supplemental Material}

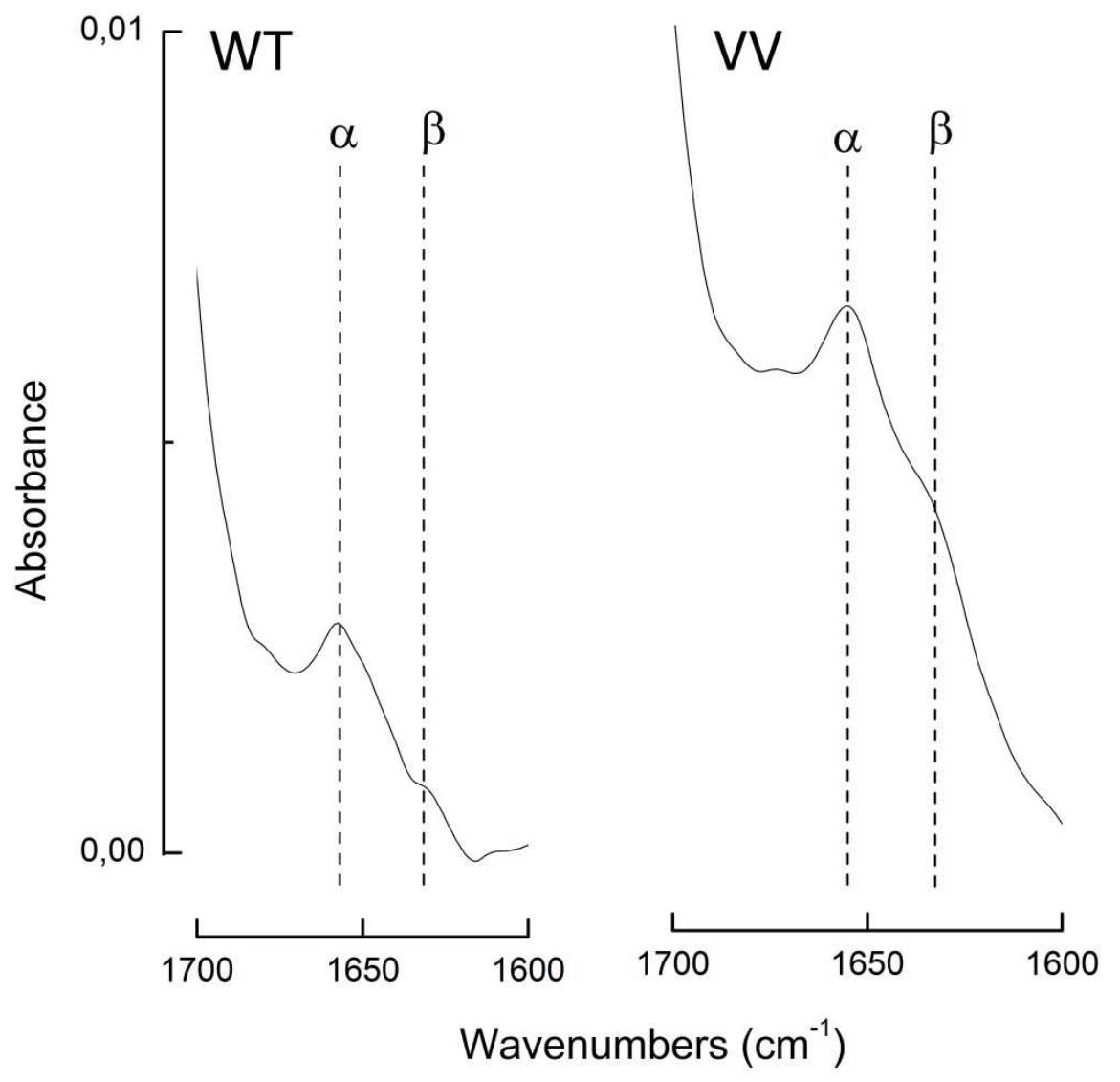

Figure S1: ATR spectra on diamond crystal of VAMP2 ${ }_{\mathrm{TM} 22}$ (WT or VV mutant) inserted into DOPC multibilayers hydrated by $\mathrm{D}_{2} \mathrm{O}$. Detailed view of $\alpha$-helix and $\beta$-sheet regions at $1 / 300$. 
Table S1: Percentage of secondary structure ( $\alpha$-helix and $\beta$-sheets) for VAMP $2_{\mathrm{TM} 22} \mathrm{WT}$ and VV mutant in DOPC, DOPC/DOPS (93:7), DOPC/DOPS/Cholesterol (49:7:44), and DOPC/DOPS/Cholesterol (73:7:20) membranes, as obtained from ATR spectra. Deconvolution of ATR spectra was accomplished by peaksolve (GRAMS, version 3.0). The accuracy is estimated to within ca. $\pm 5 \% . T=25^{\circ} \mathrm{C}$.

\begin{tabular}{|c|c|c|c|c|}
\hline \multirow[t]{2}{*}{ Peptide } & \multirow[t]{2}{*}{ Lipid composition } & \multicolumn{3}{|c|}{$\begin{array}{c}\% \text { of secondary structure elements } \\
\beta \text {-sheets/ } \alpha \text {-helix at peptide/lipid ratio }\end{array}$} \\
\hline & & $1 / 300$ & $1 / 50$ & $1 / 20$ \\
\hline \multirow{4}{*}{ VAMP $2_{\text {TM} 22} \mathrm{WT}$} & DOPC & $7 / 56$ & $34 / 50$ & $72 / 25$ \\
\hline & $\begin{array}{l}\text { DOPC/DOPS } \\
93 / 7(w / w \%)\end{array}$ & $53 / 23$ & $39 / 43$ & $21 / 51$ \\
\hline & $\begin{array}{l}\text { DOPC/DOPS/Cholesterol } \\
73 / 7 / 20(\mathrm{w} / \mathrm{w} / \mathrm{w} \%)\end{array}$ & $38 / 46$ & $33 / 35$ & $37 / 39$ \\
\hline & $\begin{array}{l}\text { DOPC/DOPS/Cholesterol } \\
49 / 7 / 44(\mathrm{w} / \mathrm{w} / \mathrm{w} \%)\end{array}$ & $69 / 11$ & $45 / 46$ & $59 / 21$ \\
\hline \multirow{4}{*}{ VAMP $2_{\text {TM22 }} \mathrm{VV}$} & DOPC & $25 / 55$ & $29 / 51$ & $72 / 22$ \\
\hline & $\begin{array}{l}\text { DOPC/DOPS } \\
93 / 7(w / w \%)\end{array}$ & $51 / 30$ & $38 / 40$ & $33 / 40$ \\
\hline & $\begin{array}{l}\text { DOPC/DOPS/Cholesterol } \\
73 / 7 / 20(\mathrm{w} / \mathrm{w} / \mathrm{w} \%)\end{array}$ & $64 / 22$ & $51 / 28$ & $57 / 22$ \\
\hline & $\begin{array}{l}\text { DOPC/DOPS/Cholesterol } \\
49 / 7 / 44(\mathrm{w} / \mathrm{w} / \mathrm{w} \%)\end{array}$ & $61 / 21$ & $49 / 40$ & $58 / 25$ \\
\hline
\end{tabular}

Table S2: Frequencies of the $v_{\mathrm{s}}\left(\mathrm{CH}_{2}\right)$ and $v_{\mathrm{as}}\left(\mathrm{CH}_{2}\right)$ bands of lipids chains in presence or in absence of VAMP $2_{\mathrm{TM} 22} \mathrm{VV}\left(\mathrm{G}_{100} \mathrm{~V} / \mathrm{C}_{103} \mathrm{~V}\right.$ mutant $)$. Composition of multibilayers: DOPC, DOPC/DOPS (93/7) or DOPC/DOPS/Cholesterol (49/7/44).

\begin{tabular}{|c|l|c|c|c|c|c|c|}
\cline { 3 - 8 } \multicolumn{2}{c|}{} & \multicolumn{3}{c|}{$v_{\text {as }}\left(\mathrm{CH}_{2}\right) \mathrm{cm}^{-1}$} & \multicolumn{3}{c|}{$v_{\mathrm{s}}\left(\mathrm{CH}_{2}\right) \mathrm{cm}^{-1}$} \\
\hline \multirow{2}{*}{ Peptide } & $\begin{array}{c}\text { Peptide/Lipid } \\
\text { Ratios }\end{array}$ & DOPC & $\begin{array}{c}\text { DOPC/ } \\
\text { DOPS }\end{array}$ & $\begin{array}{c}\text { DOPC/DOPS/ } \\
\text { CHOL }\end{array}$ & DOPC & $\begin{array}{c}\text { DOPC/ } \\
\text { DOPS }\end{array}$ & $\begin{array}{c}\text { DOPC/DOPS/ } \\
\text { CHOL }\end{array}$ \\
\hline \multirow{3}{*}{ WT } & No peptide & 2921.2 & 2924.4 & 2925.5 & 2851.7 & 2852.8 & 2853.2 \\
\hline \multirow{3}{*}{ VV } & $1 / 300$ & 2924.1 & 2924.5 & 2925.6 & 2853.6 & 2854.6 & 2854.6 \\
\hline & $1 / 50$ & 2924.3 & 2924.7 & 2925.5 & 2854.2 & 2854.4 & 2854.6 \\
\hline & $1 / 20$ & 2924.6 & 2924.6 & 2925.6 & 2854.3 & 2854.3 & 2854.7 \\
\hline & $1 / 300$ & 2924.3 & 2924.4 & 2925.6 & 2854.2 & 2854.3 & 2854.2 \\
\hline
\end{tabular}

